\title{
Core Temperature and Sweat Responses in Professional Women's Tennis Players During Tournament Play in the Heat
}

\author{
Melissa L. Tippet, MA; John R. Stofan, MS; Magie Lacambra, MEd, ATC; \\ Craig A. Horswill, PhD
}

\author{
Gatorade Sports Science Institute, Barrington, IL
}

Context: Tennis is often played in hot, humid environments, intensifying the thermoregulatory strain placed on the athletes. As a safety measure, some tennis organizations allow for a 10minute break in play between the second and third sets when environmental conditions are extreme. However, the actual effect of these breaks in reducing core temperature is unknown.

Objective: To determine change in core temperature after a 10-minute break in play and assess fluid balance in professional female tennis players during tournament matches in the heat.

Design: Cross-sectional study.

Setting: A Women's Tennis Association Tour-sanctioned outdoor tournament on hard courts under hot conditions $\left(30.3^{\circ} \mathrm{C}\right.$ $\left.\pm 2.3^{\circ} \mathrm{C}\right)$.

Patients or Other Participants: Seven professional tennis players. Main Outcome Measure(s): Change in core temperature after a 10-minute break in tournament play, fluid intake, and sweat losses during match play.
Results: Core temperature was reduced from $38.92^{\circ} \mathrm{C}$ to $38.67^{\circ} \mathrm{C}$ (change of $-0.25^{\circ} \mathrm{C} \pm 0.20^{\circ} \mathrm{C}$ ) when a break was taken $(P=.02)$. Mean sweat rate during match play was $2.0 \pm 0.5 \mathrm{~L} / \mathrm{h}$. During that time, mean fluid intake was 1.5 $\pm 0.5 \mathrm{~L} / \mathrm{h}$, resulting in a $1.2 \% \pm 1.0 \%$ reduction in body mass.

Conclusions: Female professional tennis players are subjected to high heat loads during match play in hot environments. However, a 10-minute break in play decreased core temperature in 6 of 7 players by an average of $0.25^{\circ} \mathrm{C}$, indicating that the break provides practical benefits in the field. Furthermore, although mean sweat rate in this group of female tennis players was high, most athletes were still able to minimize mass loss to less than $2 \%$ of their prematch weight.

Key Words: environmental physiology, thermoregulation, fluid balance

\section{Key Points}

- Mean core temperature throughout match play was $38.65^{\circ} \mathrm{C} \pm 0.20^{\circ} \mathrm{C}$, and peak temperature was $39.13^{\circ} \mathrm{C} \pm 0.34^{\circ} \mathrm{C}$. Average temperature rise was $1.33^{\circ} \mathrm{C} \pm 0.41^{\circ} \mathrm{C}$ after $78.7 \pm 31.4$ minutes of play.

- After a 10 -minute break, core temperature decreased by $0.25^{\circ} \mathrm{C} \pm 0.20^{\circ} \mathrm{C}$ in 6 of 7 participants, including all whose temperatures were above $39.0^{\circ} \mathrm{C}$.

- The players generally maintained hydration status during the match, losing a little more than $1 \%$ of their prematch body mass.

$\mathrm{C}$ ore body temperature response during high-intensity, intermittent efforts, such as tennis, has received relatively little attention to date and has been reported only twice during sanctioned competition. Bergeron et al ${ }^{1}$ examined the correlation between prematch hydration status, as indicated by urine specific gravity (USG), and core temperature in 14-year-old junior boys' players, and found a positive relationship between USG and both the first during-play temperature and the final core temperature readings at the end of match play. The authors recorded only 2 during-play body temperature measurements and noted that all singles matches were "fairly easy straight sets wins," with a mean match duration of 79 minutes, thereby potentially limiting the validity of the findings to all tennis players. Hornery et $\mathrm{al}^{2}$ found correlations between core temperature and match characteristics in professional men's players. They reported relationships between the players' temperatures and time between both points and games, increases in shots per rally, and rally duration. In both competitive situations, only males were evaluated.

Before these 2 studies, research on the thermal responses of tennis players was conducted during practice sessions. In all cases, the mean core temperature of the athletes during practice sessions was lower than that of both juniors ${ }^{1}$ and professional players ${ }^{2}$ during sanctioned match play. Morante and Brotherhood 3 investigated temperature responses in male and female adult tennis players of various abilities to environmental conditions. They concluded that tennis players did not face high levels of thermoregulatory strain because overall exercise intensity was moderate ${ }^{3}$ and players were able to adequately thermoregulate by increasing sweat rate and decreasing workload. ${ }^{4}$ Bergeron et al ${ }^{5}$ also reported lower mean body temperatures in adolescent athletes during training sessions relative to those reported during match play, ${ }^{1,2}$ 


\begin{tabular}{|c|c|c|c|c|}
\hline \multirow[b]{2}{*}{ Factor } & \multicolumn{4}{|c|}{ Day } \\
\hline & 1 & 2 & 3 & 4 \\
\hline $\begin{array}{l}\text { Mean wet bulb globe temperature } \\
\text { during match play, }{ }^{\circ} \mathrm{C}\end{array}$ & 30.64 & 31.75 & 31.48 & 29.08 \\
\hline $\begin{array}{l}\text { Wet bulb globe temperature range } \\
\text { during match play, }{ }^{\circ} \mathrm{C}\end{array}$ & 29.22-31.39 & $30.67-32.56$ & $30.78-32.39$ & $24.39-32.00$ \\
\hline Players studied, $\mathrm{n}$ & 1 & 2 & 1 & 3 \\
\hline Time of match play & Midmorning & $\begin{array}{l}\text { Midmorning (1), early } \\
\text { afternoon (1) }\end{array}$ & Early afternoon & $\begin{array}{l}\text { Early afternoon (2), early } \\
\quad \text { evening (1) }\end{array}$ \\
\hline
\end{tabular}

particularly when the athletes drank a carbohydrateelectrolyte solution.

As a safety measure, some tennis organizations, including the Women's Tennis Association (WTA) Tour, allow for a break in play between the second and third sets of the match when the wet-bulb globe temperature (WBGT) reaches $28^{\circ} \mathrm{C}$ or higher. Prior investigations of tennis players have not accounted for formal or spontaneous rest breaks and their effect on core temperature response. In theory, a formal break should allow for a reduction in temperature through a decrease in activity level and by providing an extended opportunity for fluid intake. What is not known, however, is the extent, if any, these short breaks have on reducing body temperature during tennis competition.

Therefore, the purpose of our study was to determine the effect of a 10-minute Extreme Weather Condition (EWC) break on core temperature responses in professional adult female tennis players during sanctioned tournament play in the heat. We hypothesized that the 10-minute break would reduce core temperature. In addition, we measured sweat fluid losses to determine if they were associated with the body's temperature response. This study is important in quantifying the thermoregulatory responses of a unique group of elite tennis players who, unlike recreational and amateur players, are often unwilling to consciously reduce workload to avoid thermoregulatory strain. Unlike the previous 2 accounts of core temperature responses during sanctioned match play, ours is the first report of body temperature responses in female players.

\section{METHODS}

\section{Participants}

A convenient sample of 10 professional female tennis players, identified and recruited by the WTA, volunteered for this descriptive study. Three players did not take an extended break in play and were therefore considered noncompliant; thus, their data were not included in subsequent analyses. Physical characteristics of the remaining 7 players were age $=23.4 \pm 4.5$ years (range, 18 30 years), height $=170 \pm 3 \mathrm{~cm}$ (range, $168-175 \mathrm{~cm})$, and mass $=67.6 \pm 7.7 \mathrm{~kg}$ (range, $59.5-83.8 \mathrm{~kg}$ ). Each athlete was told that her physiologic responses to match play would be monitored. The study was approved by the Human Subjects in Research Committee for the Gatorade Sports Science Institute, and each volunteer provided informed consent before participating.

\section{Experimental Design}

All measurements were taken in July 2006 at a sanctioned WTA Tour Tier III tournament. At the time of data collection, the WTA Tour classified each event in a 4-tier system based on the prize money available (Tier I events had the largest purses, whereas Tier IV offered the smallest purses); however, the tier system did not necessarily reflect the talent or rank of the athletes playing. All matches were played outdoors on hard courts. Environmental heat stress was assessed throughout each day with a WBGT meter (QUESTemp 36; Quest Technologies, Oconomowoc, WI) placed near the players' chairs on center court. The WBGT and dry globe bulb temperatures were recorded at 30-minute intervals. Over the 4 days, the daily average WBGT during tournament play was $30.3^{\circ} \mathrm{C} \pm 2.3^{\circ} \mathrm{C}$ (range, $26.1^{\circ} \mathrm{C}-$ $31.9^{\circ} \mathrm{C}$ ), an environment in which guidelines from both the American College of Sports Medicine ${ }^{6}$ and the National Athletic Trainers' Association (NATA) 7 recommend practice and competition be delayed or canceled or, if necessary, played under caution. Daily environmental conditions during tournament play are found in Table 1.

Approximately 8 to 12 hours before each player's anticipated match start time, she ingested a temperature pill, along with a small snack, to determine coretemperature changes. The ingestible temperature pill (CorTemp 2000; HQ Inc, Palmetto, FL) has previously been shown to be a valid method for assessing core body temperature 8,9 and is a convenient, relatively noninvasive method, particularly suitable for field measurements.

Before match play, the athletes reported to the women's locker room, where researchers confirmed that the sensor was activated according to the manufacturer's instructions. At this time, each player voided to empty her bladder, and a sample of the urine was assessed for USG. The player was then weighed wearing minimal clothing (nude, undergarments only, or towel only, depending on the athlete's preference) to the nearest $0.05 \mathrm{~kg}$ on a calibrated scale (model UC-321P; A\&D Medical, Milpitas, CA). To help us accurately assess true habits, each player provided her own hydration and nutritional products. To determine fluid intake, we individually weighed any bottle the athlete would potentially drink from to the nearest gram. Additionally, any food that might be consumed by a player during the match was also weighed in its wrapper to the nearest gram before the match.

To try to standardize the timing of the baseline coretemperature measurement, we took the initial measurement after the WTA Tour-allotted 5-minute warm-up and immediately before match play began. Measurements 


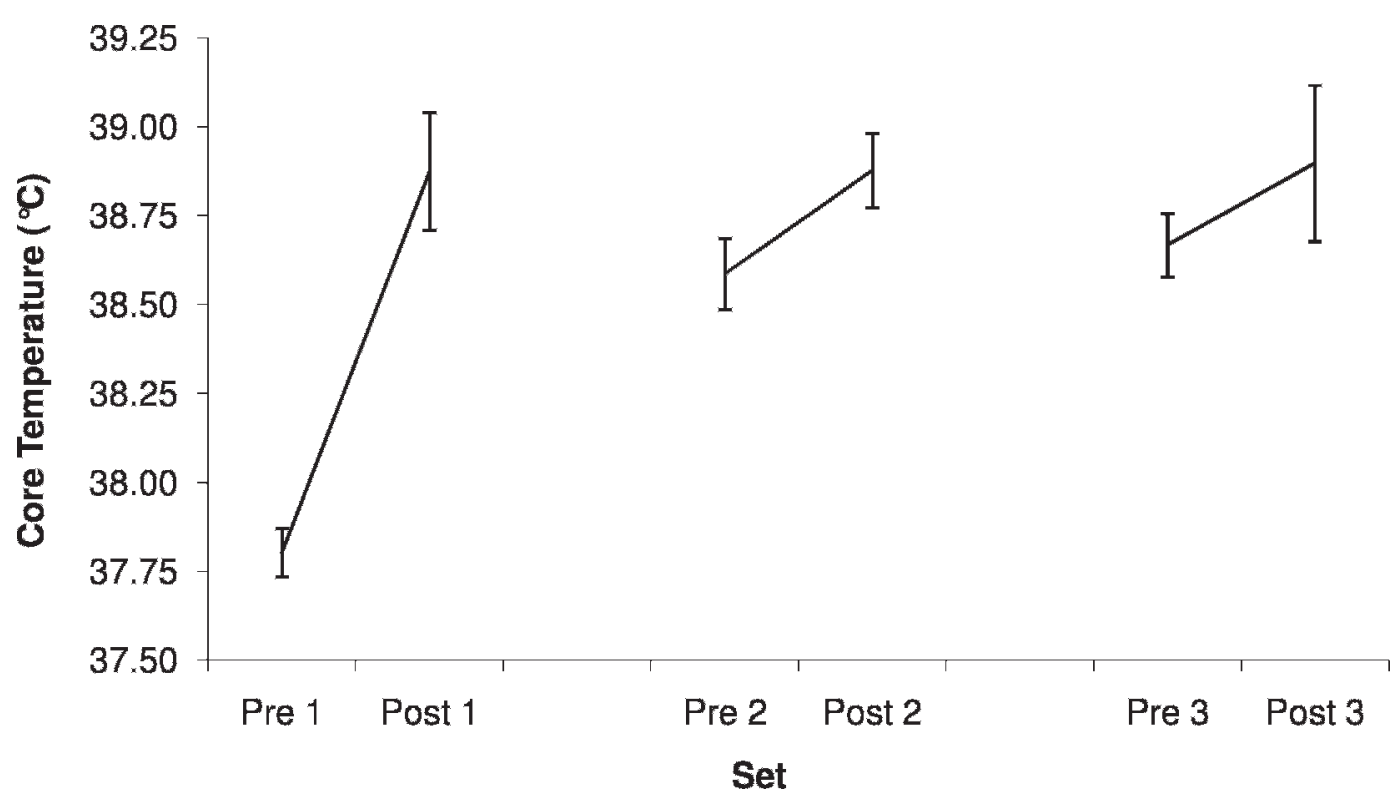

Figure 1. Mean core temperature immediately before and after each set. Note: $\mathbf{n}$ for sets 1 and 2 was 7 ; $\mathbf{n}$ for set 3 was 3 .

during match play were then taken by a researcher sitting on court during each 90 -second side-changeover break and during each 120 -second break between sets. Temperature measurements were also taken both before and after any bathroom breaks (allowed between sets) and before and after any EWC breaks (allowed only between sets 2 and 3) and at the completion of match play. To help ensure that temperature readings were reliable, at least 2 measurements were taken each time. All temperature readings were within a reasonable, expected range and none fluctuated with fluid ingestion. During match play, each player drank ad libitum from her preweighed bottles and any voided urine was collected and weighed.

After the match, the athlete returned to the locker room, towel dried as completely as possible, and was weighed again on the same scale in the same minimal clothing. The fluid bottles, which were collected immediately after the match, were also reweighed, along with any remaining food and wrappers.

\section{USG and Sweat-Loss Analyses}

The urine collected before play was measured for USG using a handheld clinical refractometer (model A300CL; Atago Co, Ltd, Tokyo, Japan). Individual sweat losses were calculated from the prematch to postmatch change in body mass and corrected for fluid and food intake and any urine loss if applicable.

\section{Statistical Analysis}

Data were analyzed using SPSS statistical software (version 14.0; SPSS Inc, Chicago, IL). All measurements are reported as mean \pm SD unless otherwise noted. We used a $t$ test to determine significance in core-temperature change prebreak to postbreak. To determine significance in coretemperature change between sets, we calculated a 2-way analysis of variance to identify main effects due to match, time, and the match $\times$ time interaction. A Bonferroni correction was used to adjust for multiple comparisons.
Pearson product moment correlations were also obtained. Statistical significance was set at $P<.05$. Effect-size (ES) estimates were calculated according to Cohen, 10 and $95 \%$ confidence intervals (CIs) are reported for means.

\section{RESULTS}

\section{Core Temperature}

Although the number depended on the length of the match, an average of $14 \pm 4$ (range, 9-18) core-temperature readings were recorded for each player from prematch to postmatch. Prematch core temperature was $37.80^{\circ} \mathrm{C} \pm$ $0.18^{\circ} \mathrm{C}$. Core temperature (including prematch to postmatch measurements) during the $119.9 \pm 40.1$ minutes of match play was $38.65^{\circ} \mathrm{C} \pm 0.20^{\circ} \mathrm{C}$, with a peak of $39.13^{\circ} \mathrm{C} \pm$ $0.34^{\circ} \mathrm{C}$. As expected, the players' core temperature increased during the first set (change $=1.07^{\circ} \mathrm{C} \pm 0.39^{\circ} \mathrm{C} ; P<.001$, ES $=3.48,95 \% \mathrm{CI}=0.71,1.44)$. However, as demonstrated in Figure 1, core temperature remained elevated in set 2 relative to set 1 (difference $=0.39^{\circ} \mathrm{C} \pm 0.30^{\circ} \mathrm{C} ; P=.01, \mathrm{ES}=1.51$, $95 \% \mathrm{CI}=0.10,0.68)$, as well as in set 3 relative to set 1 (difference $=0.44^{\circ} \mathrm{C} \pm 0.55^{\circ} \mathrm{C} ; P=.02, \mathrm{ES}=1.68,95 \% \mathrm{CI}$ $=0.07,0.82$ ). Of the 7 players who opted for a 10 -minute break during the match, 4 were eligible to take advantage of the EWC rule and did so; the other 3 players took a bathroom break. Core temperature decreased $0.30^{\circ} \mathrm{C} \pm$ $0.14^{\circ} \mathrm{C}$ after an EWC break and $0.17^{\circ} \mathrm{C} \pm 0.27^{\circ} \mathrm{C}$ after a bathroom break. Although the purpose of a bathroom break may not be the same traditionally as an EWC rule break, the athletes' behaviors appeared to be the same during the time periods (towel dry, change of clothes, etc), as did the time used (10-minute break). Therefore, for statistical purposes, responses from both the bathroom break and the EWC rule break were combined to form a single break group. Results of the $t$ test showed that core temperature was reduced when a break was taken (change $=-0.25^{\circ} \mathrm{C} \pm 0.20^{\circ} \mathrm{C} ; P=.02$, ES $=0.76,95 \% \mathrm{CI}=0.06,0.43)$. Individual core-temperature responses of the 7 athletes who took 10-minute breaks during competition are shown in Figure 2. We found no correla- 


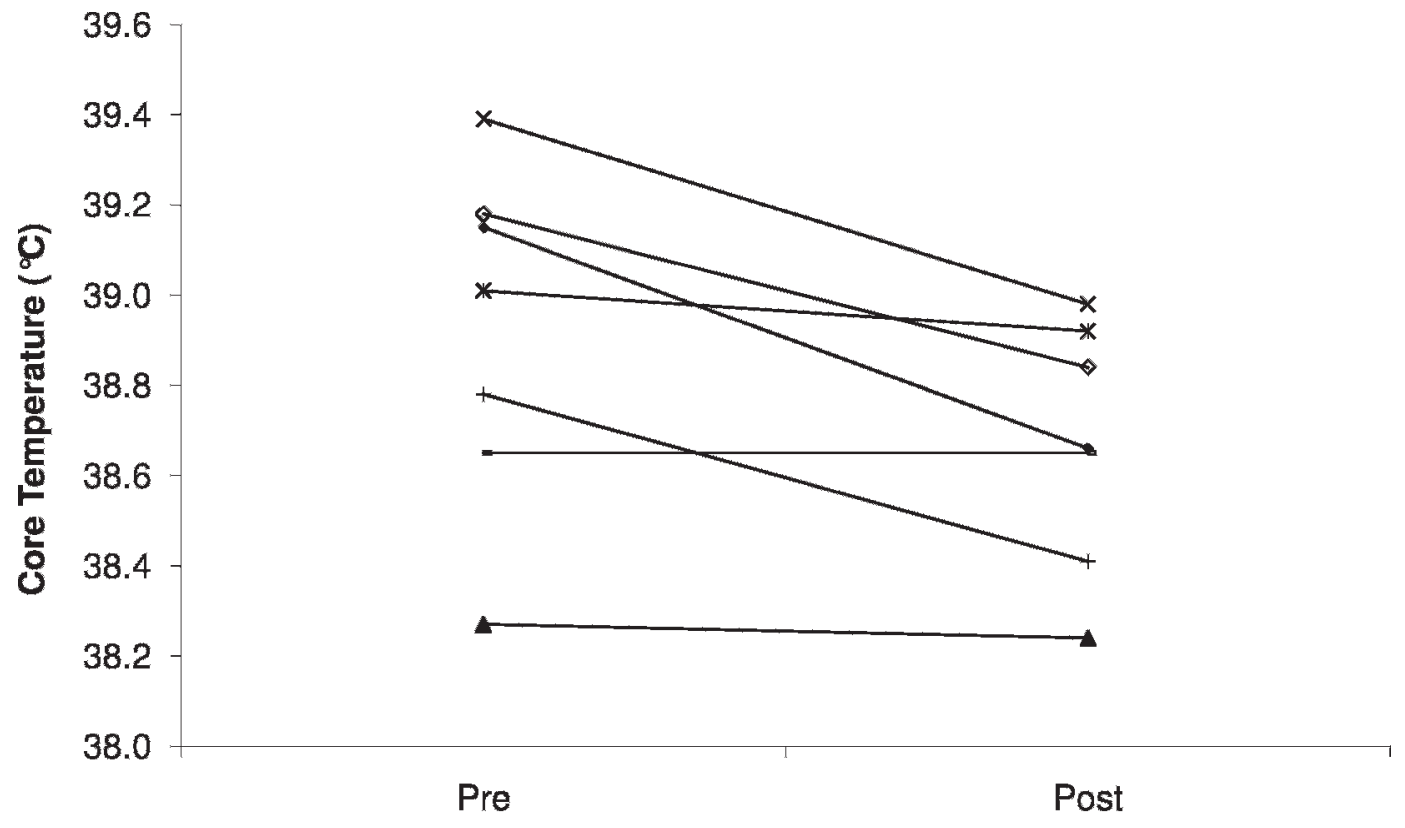

Break (10 min)

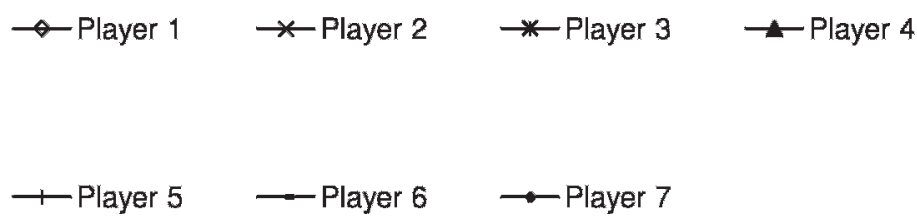

Figure 2. Individual core temperature responses of the 7 players immediately before and after the 10-minute break. Note: Players 1, 3, 5, and 7 took an Extreme Weather Condition break. Players 1, 5, and 7 took their breaks in an air-conditioned facility; player 3 was in a nonair-conditioned facility. Players 2, 4, and 6 took a bathroom break.

tions between the change in core temperature and prematch hydration status (USG) $(r=0.03, P=.96)$, sweat rate $(r=$ $0.08, P=.86)$, fluid deficit ( $r=0.61, P=.15)$, and match duration $(r=0.27, P=.56)$. We also noted no correlations between peak core temperature and prematch hydration status (USG) $(r=-0.08, P=.87)$, sweat rate $(r=-0.51$, $P=.24)$, and fluid deficit $(r=-0.01, P=.98)$, but a correlation was detected between peak core temperature and match duration $(r=0.77, P=.04)$.

\section{Fluid Balance}

Prematch hydration status was determined using a urine sample collected before the match and indicated that all 7 players began the match with a USG $\geq 1.020$ (USG $=$ $1.025 \pm 0.003)$. Prematch body mass was $67.6 \pm 7.7 \mathrm{~kg}$ and players lost an average $0.8 \pm 0.7 \mathrm{~kg}$ over the $119.9 \pm$ 40.6 minutes of play. Fluid intake during the match was 2.9 $\pm 0.9 \mathrm{~L}$. Calculated sweat rate was $2.0 \pm 0.5 \mathrm{~L} / \mathrm{h}(1.1 \pm$ $0.2 \mathrm{~L} / \mathrm{m}^{2} / \mathrm{h}$ ). Fluid deficit during the match was $0.8 \pm 0.7 \mathrm{~L}$, reflecting an acute reduction of $1.2 \pm 1.1 \%$ in body mass.

\section{DISCUSSION}

\section{Core Temperature}

An increase in core temperature can contribute to several negative consequences in athletes, including a potential decrease in performance. ${ }^{11-14}$ In tennis players, increases in core temperature during sanctioned match play have been positively correlated with the time between points and games and the number of shots per rally and overall rally duration ${ }^{2}$ - all variables that can influence match dynamics.

Core temperature from prematch to postmatch for the tennis players in our study was $38.65^{\circ} \mathrm{C} \pm 0.20^{\circ} \mathrm{C}$. This value is higher than the previously reported core-temperature responses in other adult tennis players $\left(38.4^{\circ} \mathrm{C}\right.$ and $\left.38.45^{\circ} \mathrm{C}\right) .3,4$ Although Hornery et $\mathrm{al}^{2}$ did not report mean core temperature throughout tournament match play, the professional men's players' mean peak temperature $\left(38.9^{\circ} \mathrm{C}\right)$ was higher than mean peak temperatures reported in nonsanctioned match play situations ${ }^{4,15}$ and more similar to what we observed for the women's players' peak $\left(39.13^{\circ} \mathrm{C} \pm 0.34^{\circ} \mathrm{C}\right)$ as well. A comparison of available core-temperature data in tennis players is provided in Table 2. We suspect the differences between sanctioned and nonsanctioned tennis play could be due to heightened environmental stress, greater intensity of effort, or a combination of the factors.

In the current study, the average temperature rise from prematch to peak was $1.33^{\circ} \mathrm{C} \pm 0.41^{\circ} \mathrm{C}$ and occurred after $78.7 \pm 31.4$ minutes of play. After a 10 -minute break in play, core temperature decreased by $0.25^{\circ} \mathrm{C} \pm 0.20^{\circ} \mathrm{C}$ for 6 of the 7 participants (Figure 2). Also, all 4 players whose core temperature was above $39.0^{\circ} \mathrm{C}$ immediately before the 


\begin{tabular}{|c|c|c|c|c|c|c|c|}
\hline \multirow[b]{2}{*}{ Activity } & \multicolumn{7}{|c|}{ Study } \\
\hline & $\begin{array}{c}\text { Current Study } \\
\text { Sanctioned } \\
\text { Tournament } \\
\text { Matches }\end{array}$ & $\begin{array}{l}\text { Hornery } \\
\text { et al }{ }^{2} \\
\text { Sanctioned } \\
\text { Tournament } \\
\text { Matches } \\
\text { (Men's) }\end{array}$ & $\begin{array}{l}\text { Bergeron } \\
\text { et al }{ }^{1} \\
\text { Sanctioned } \\
\text { Tournament } \\
\text { Matches } \\
\text { (Junior } \\
\text { Men's) }\end{array}$ & $\begin{array}{l}\text { Morante and } \\
\text { Brotherhood } \\
\text { Simulated } \\
\text { Singles } \\
\text { Matches }\end{array}$ & $\begin{array}{l}\text { Morante and } \\
\text { Brotherhood }{ }^{3} \\
\text { Simulated } \\
\text { Singles } \\
\text { Matches }\end{array}$ & $\begin{array}{c}\text { Bergeron } \\
\text { et al }{ }^{5} \\
\text { Tennis-Specific } \\
\text { Training } \\
\text { Sessions } \\
\text { (Water Trial) }\end{array}$ & $\begin{array}{c}\text { Bergeron } \\
\text { et al5 } \\
\text { Tennis-Specific } \\
\text { Training } \\
\text { Sessions } \\
\text { (Carbohydrate- } \\
\text { Electrolyte } \\
\text { Beverage Trial) }\end{array}$ \\
\hline \multicolumn{8}{|l|}{ Measurement } \\
\hline Wet bulb globe temperature, ${ }^{\circ} \mathrm{C}$ & 29.9 & $32.0 \mathrm{a}$ & 29.6 & 22.5 & 24.4 & 26.6 & 26.3 \\
\hline Players studied, $\mathrm{n}$ & 10 & 6 & 8 & 25 & $7 \mathrm{~b}$ & 14 & 14 \\
\hline \multicolumn{8}{|l|}{ Rectal temperature, ${ }^{\circ} \mathrm{C}$} \\
\hline Mean & 38.7 & NA & $38.7 \mathrm{c}$ & 38.45 & 38.4 & 38.20 & 37.97 \\
\hline Peak & 39.1 & 38.9 & NA & 38.72 & NA & $38.5^{c}$ & $38.3^{c}$ \\
\hline Change after 10 -min break & $0.25^{d}$ & NA & $0.3 \mathrm{c}, \mathrm{e}$ & NA & NA & NA & NA \\
\hline Body-weight reduction, $\%$ & 0.9 & 1.05 & 0.9 & NA & NA & 0.9 & 0.5 \\
\hline \multicolumn{8}{|l|}{ Abbreviation: NA, not available. } \\
\hline $\begin{array}{l}\text { a Wet bulb temperature. } \\
{ }^{b} \text { Only data from elite females w } \\
{ }^{c} \text { Temperature estimated based } \\
\text { d } 10 \text {-minute break during match } \\
{ }^{\text {e }} 10 \text {-minute break postmatch pla }\end{array}$ & $\begin{array}{l}\text { vere included. } \\
\text { on data. } \\
\text { play. }\end{array}$ & & & & & & \\
\hline
\end{tabular}

break experienced a reduction below the $39.0^{\circ} \mathrm{C}$ threshold that some researchers consider the safety cutoff point during laboratory work. This finding leads us to believe that a 10-minute break may be beneficial to reduce core temperature, especially in those at greatest risk for progressing to hyperthermia. Bergeron et al ${ }^{1}$ measured core temperature in adolescent boys 10 minutes after match play and found that it had not decreased significantly at that point. With 8 participants and an estimated decrease of $0.3^{\circ} \mathrm{C}$, we suspect that variability in the temperature change noted and the statistical analysis used (a repeatedmeasures analysis of variance) may have contributed to their inability to find a statistical reduction in core temperature.

Several limitations may have influenced the degree to which the players cooled within the 10-minute break and, in turn, may have hindered a greater reduction. One inconsistency was that the environmental conditions during which the 10-minute break was taken were not standardized among players. Because the time limit of the break is strictly enforced, it was not always feasible or practical for the athlete to move to an air-conditioned facility; therefore, although some players were able to rest in the airconditioned locker room or bathroom, another player was only able to access a non-air-conditioned bathroom. An additional factor was that the 10-minute break included physical activity and heat exposure as the athlete moved (ie, walked quickly) to a cooler environment. If the intent is to reduce clinical risk related to elevated core body temperature, systematically testing duration and strategies for cooling during such breaks in tennis play in the heat is warranted.

\section{Hydration}

The athletes in our study generally maintained hydration status during competitive play, losing a little more than $1 \%$ of their prematch body mass. Although it is possible the athletes changed their behavior in response to being studied, we saw no indication of this, and the mean change in body mass we noted is similar to the losses in adolescent boys and men during sanctioned match play,2,16 simulated postmatch play in collegiate tennis players, ${ }^{15}$ and postpractice body-mass losses in adolescent tennis players during practice. ${ }^{5}$ Dehydration levels in our study were low, but previous research suggests that athletes who are minimally dehydrated still experience increased core temperatures. Claremont et al17 reported that rectal temperature increased $0.7^{\circ} \mathrm{C}$ in participants who lost just $0.9 \%$ of body mass. Possibly more meaningful to an athlete is the finding that a $1 \%$ loss in body mass during a professional tennis match was correlated with changes in serve characteristics. ${ }^{2}$

Before starting the match, all 7 players had a USG of 1.020 or higher. Urine specific gravity is a valid measure of an individual's hydration status and has been recommended by the NATA as a criterion for estimating hydration status. 18 Using these recommendations, the participants were projected to have "significant dehydration."19 Inadequate hydration at the start of activity may present a greater problem to athletes if during-activity sweat losses are added to the $3 \%$ to $5 \%$ dehydration (as predicted by the NATA) associated with a USG greater than 1.020, because these levels of fluid loss can lead to decrements in both performance and safety. 19

The mean sweat rate of these female athletes, even when corrected for body surface area $\left(1.1 \pm 0.2 \mathrm{~L} / \mathrm{m}^{2} / \mathrm{h}\right)$, appears to be one of the highest yet reported for tennis players. Sweat rates for adolescents (mean age $=15.1$ years) during practice were calculated to be $0.67 \mathrm{~L} / \mathrm{m}^{2} / \mathrm{h} .{ }^{5}$ In the adult population, sweat rates for collegiate tennis players competing in a simulated tennis tournament were also lower $\left(0.6 \mathrm{~L} / \mathrm{m}^{2} / \mathrm{h}\right), 15$ as were sweat rates in a group of adult female tennis players of various abilities (approximately $0.75 \mathrm{~L} / \mathrm{m}^{2} / \mathrm{h}$ ). ${ }^{3}$ Looking beyond the tennis community, these sweat rates were also high compared with athletes in 
other sports. Sweat rates of $0.45 \mathrm{~L} / \mathrm{m}^{2} / \mathrm{h}$ have been reported in female soccer players, ${ }^{20} 0.49 \mathrm{~L} / \mathrm{m}^{2} / \mathrm{h}$ in female basketball players, 20 and even $0.70 \mathrm{~L} / \mathrm{m}^{2} / \mathrm{h}$ in National Collegiate Athletic Association Division I collegiate football players. ${ }^{21}$ We speculate that the rates we observed are due to a combination of factors, including optimal fitness level and heat acclimatization; both assumptions are based on the fact that measurements were taken at a tournament in the middle of the tennis season (July). In addition, maintaining body fluids (ie, hydration status) may also have helped the athletes to maintain high sweat rates throughout the match in combination with intense play and hot environmental conditions.

In summary, we are the first to determine the thermal effect of a 10-minute break during play, finding a significant decrease in core temperature. Measures of fluid balance showed that this group of professional women's tennis players was able to replace most of their fluid losses, incurring an average body mass deficit of only $1.2 \%$ in approximately 120 minutes of match play in the heat. As recent researchers have shown, thermoregulation may be a concern for tennis players during sanctioned match play. Thus, future investigators should systematically address strategies to reduce this strain. Additionally, we need to determine the effect of a reduced core temperature after a 10-minute break on both the safety and the physical performance of tennis athletes.

\section{ACKNOWLEDGMENTS}

We thank Ms Amber Donaldson and Ms Carole Doherty of the Sony Ericsson WTA Tour for their assistance and the WTA athletes who participated in the study. We also thank Beth StoverMooradian, MS, and JohnEric Smith, PhD, for their assistance with data collection.

\section{REFERENCES}

1. Bergeron MF, McLeod KS, Coyle JF. Core body temperature during competition in the heat: national boys' $14 \mathrm{~s}$ junior tennis championships. Br J Sports Med. 2007;41(11):779-783.

2. Hornery DJ, Farrow D, Mujika I, Young W. An integrated physiological and performance profile of professional tennis. Br J Sports Med. 2007;41(8):531-536.

3. Morante SM, Brotherhood JR. Air temperature and physiological and subjective responses during competitive singles tennis. Br J Sports Med. 2007;41(11):773-778.

4. Morante SM, Brotherhood JR. Autonomic and behavioural thermoregulation in tennis. Br J Sports Med. 2008;42(8):679-685.
5. Bergeron MF, Waller JL, Marinik EL. Voluntary fluid intake and core temperature responses in adolescent tennis players: sports beverage versus water. Br J Sports Med. 2006;40(5):406-410.

6. American College of Sports Medicine, Armstrong LE, Casa DJ, et al. American College of Sports Medicine position stand: exertional heat illness during training and competition. Med Sci Sports Exerc. 2007;39(3):556-572.

7. Binkley HM, Beckett J, Casa DJ, Kleiner DM, Plummer PE. National Athletic Trainers' Association position statement: exertional heat illnesses. J Athl Train. 2002;37(3):329-343.

8. Byrne C, Lim CL. The ingestible telemetric body core temperature sensor: a review of validity and exercise applications. $\mathrm{Br} J$ Sports Med. 2007;41(3):126-133.

9. Casa DJ, Becker SM, Ganio MS, et al. Validity of devices that assess body temperature during outdoor exercise in the heat. J Athl Train. 2007;42(3):333-342.

10. Cohen J. Statistical Power Analysis for the Behavioral Sciences. Hillsdale, NJ: Lawrence Erlbaum Associates; 1988:25-27.

11. Gonzalez-Alonso J, Teller C, Andersen SL, Jensen FB, Hyldig T, Nielsen B. Influence of body temperature on the development of fatigue during prolonged exercise in the heat. $J$ Appl Physiol. 1999;86(3):1032-1039.

12. Morris JG, Nevill ME, Williams C. Physiological and metabolic responses of female games and endurance athletes to prolonged, intermittent, high-intensity running at $30^{\circ}$ and $16^{\circ} \mathrm{C}$ ambient temperatures. Eur J Appl Physiol. 2000;81(1-2):84-92.

13. Nybo L, Jensen T, Nielsen B, Gonzalez-Alonso J. Effects of marked hyperthermia with and without dehydration on $\mathrm{VO}_{2}$ kinetics during intense exercise. J Appl Physiol. 2001;90(3):1057-1064.

14. Nybo L, Nielsen B. Hyperthermia and central fatigue during prolonged exercise in humans. J Appl Physiol. 2001;91(3):1055-1060.

15. Bergeron MF, Maresh CM, Armstrong LE, et al. Fluid-electrolyte balance associated with tennis match play in a hot environment. Int J Sport Nutr. 1995;5(3):180-193.

16. Bergeron MF. Heat cramps: fluid and electrolyte challenges during tennis in the heat. J Sci Med Sport. 2003;6(1):19-27.

17. Claremont AD, Nagle F, Reddan WD, Brooks GA. Comparison of metabolic, temperature, heart rate and ventilatory responses to exercise at extreme ambient temperatures $\left(0^{\circ}\right.$ and $\left.35^{\circ} \mathrm{C}\right)$. Med $\mathrm{Sci}$ Sports. 1975;7(2):150-154.

18. Bartok C, Schoeller DA, Sullivan JC, Clark RR, Landry GL. Hydration testing in collegiate wrestlers undergoing hypertonic dehydration. Med Sci Sports Exerc. 2004;36(3):510-517.

19. Casa DJ, Armstrong LE, Hillman SK, et al. National Athletic Trainers' Association position statement: fluid replacement for athletes. J Athl Train. 2000;35(2):212-224.

20. Broad EM, Burke LM, Cox GR, Heeley P, Riley M. Body weight changes and voluntary fluid intakes during training and competition sessions in team sports. Int J Sport Nutr. 1996;6(3):307-320.

21. Stofan JR, Osterberg KL, Horswill CA, et al. Daily fluid turnover during preseason training in U.S. college football. Int J Sport Nutr Exerc Metab. 2007;17(4):340-351.

Address correspondence to Melissa L. Tippet, MA, Gatorade Sports Science Institute, 617 West Main Street, Barrington, IL 60010. Address e-mail to Melissa.Tippet@pepsico.com. 